\title{
PENGARUH TERAPI DZIKIR TERHADAP TINGKAT KECEMASAN \\ PADA PASIEN PRE DAN POST OPERASI
}

\author{
${ }^{1}$ Nurlina \\ ${ }^{2}$ Nursyamsi
}

${ }^{1}$ Departemen Keperawatan Jiwa Stikes Panrita Husada Bulukumba
${ }^{2}$ Departemen Keperawatan Jiwa Stikes Panrita Husada Bulukumba

Alamat Korespondensi:

Ns.Nurlina,S.Kep,M.Kep

Program Studi Ilmu Keperawatan

Sekolah Tinggi Ilmu Kesehatan Panrita Husada

Bulukumba, 04132514721

HP: 085398815544

Email:nurlina_bambang@yahoo.com 


\begin{abstract}
ABSTRAK
Tindakan pembedahan dan trauma pasca bedah merupakan stressor yang dapat menimbulkan reaksi fisiologis maupun psikologis bagi pasien. Reaksi psikologis berupa kecemasan biasanya timbul pada tahap pre operatif ketika pasien mengantisipasi pembedahannya dan pada tahap pasca operatif karena nyeri dan rasa tidak nyaman, perubahan citra tubuh dan fungsi tubuh. Penanganan kecemasan dengan aspek spiritual berupa pemberian terapi dzikir merupakan salah satu upaya untuk menurunkan tingkat kecemasan pada pasien pre dan post operasi. Penelitian ini menggunakan desain penelitian pra eksperimen dengan rancangan penelitian one group pre and posttest design. Sampel penelitian ini sebanyak 15 responden kelompok eksperimen yang diambil dengan metode consecutive sampling. Kelompok eksperimen mendapatkan pemberian terapi dzikir 1 kali perlakuan dengan durasi selama 12 menit. Pengumpulan data dilakukan dengan menggunakan lembar kuesioner. Analisis data yang digunakan dalam penelitian ini adalah univariat dan bivariat dengan menggunakan uji statistik uji dependent (paired sample t test). Hasil analisis menggunakan uji statistik paired sample t test dengan tingkat kepercayaan $(\alpha=0,05)$. Berdasarkan hasil uji ini, didapatkan nilai $p$ adalah 0,000 , dengan demikian $p<\alpha(0,000$ $<0,05)$. Kesimpulan dari penelitian ini adalah terdapat pengaruh pemberian terapi dzikir terhadap tingkat kecemasan pada pasien pre dan post operasi. Peneliti menyarankan agar hasil penelitian ini bisa dijadikan sebagai referensi untuk pengaplikasian dalam ruang lingkup pelayanan keperawatan khususnya penanganan kecemasan.
\end{abstract}

\title{
Kata Kunci : Terapi Dzikir, Kecemasan Pre Operasi, Kecemasan Post Operasi
}

\begin{abstract}
Postoperative surgery and trauma are stressors that can cause physiological and psychological reactions to the patient. Psychological reactions in the form of anxiety usually arise in the preoperative stage when the patient anticipates surgery and at the postoperative stage because of pain and discomfort, changes in body image and bodily functions. Handling anxiety with spiritual aspects in the form of dzikir therapy is an effort to reduce anxiety levels in patients pre and post surgery. This study used a pre-experimental research design with a one group pre and posttest design study design. The sample of this study was 15 respondents in the experimental group taken by consecutive sampling method. The experimental group received a dzikir therapy 1 time treatment with a duration of 12 minutes. Data collection is done using a questionnaire sheet. Analysis of the data used in this study is univariate and bivariate by using a paired sample t test. The results of the analysis used a statistical test paired sample t test with a level of confidence $(\alpha=0.05)$. Based on the results of this test, the $p$ value is 0,000, thus $p<\alpha(0,000<0,05)$. The conclusion of this study is that there is an effect of giving dzikir therapy to the level of anxiety in patients pre and post surgery. Researchers suggest that the results of this study can be used as a reference for application in the scope of nursing services, especially handling anxiety.
\end{abstract}

Keywords: Dhikr Therapy, Pre Operation Anxiety, Post Surgery Anxiety 


\section{PENDAHULUAN}

Menurut Carpenito dalam (Perdana \& Niswah, 2015) mengatakan bahwa tindakan pembedahan dan trauma pasca bedah merupakan stressor yang dapat menimbulkan respon, baik berupa respon fisiologis maupun psikologis. Reaksi stress fisiologis karena pembedahan maupun pasca bedah biasanya berkaitan langsung dengan pembedahan itu sendiri, lebih ekstensif tindakan pembedahan lebih besar pula respon fisiologisnya. Sedangkan respon psikologis berkaitan langsung dengan tindakan pembedahan atau pasca bedah tetapi respon yang ditunjukan dapat sangat berlebihan berupa kecemasan dan ketakutan.

Kecemasan itu sendiri merupakan reaksi pertama yang muncul atau dirasakan oleh pasien dan keluarganya disaat pasien harus dirawat mendadak atau tanpa terencana begitu mulai masuk rumah sakit. Kecemasan akan terus menyertai pasien dan keluarganya dalam setiap tindakan perawatan terhadap penyakit yang diderita pasien (Nursalam, 2016).

Menurut data dari WHO (World Health Organiton) di tahun 2015 jumlah penderita yang mengalami gangguan kecemasan sebanyak 264 miliar atau 4,6\% yang terjadi pada wanita dan $2,6 \%$ pada pria didunia. Di Amerika dlihat dari jenis kelamin didapatkan bahwa wanita cenderung lebih banyak mengalami ganguan kecemasan yaitu sebanyak 7,7\% sedangkan pada pria sebanyak $3,6 \%$ yang mengalami gangguan kecemasan. Sedangkan di Asia sebanyak 4\% dialami pada wanita dan $2,3 \%$ dialami oleh pria.

Di Indonesia sendiri terdapat 16 juta orang atau $6 \%$ penduduk indonesia mengalami gangguan mental emosional, termasuk kecemasan (Riskesdas, 2013). Jika kecemasan diluar kendali dan tidak ditangani dengan baik bisa menyebabkan depresi sehingga mengganggu pribadi maupun kehidupan sosial (ASEAN Federation for Psychiatry \& Mental Health, 2015).

Dalam menghadapi ketakutan dan kecemasan pasien pre dan post operasi kepercayaan spiritual memiliki peranan penting dengan ditingkatkannya pemberian mutu pelayanan kesehatan terutama dalam pemberian asuhan keperawatan pada aspek spiritual merupakan upaya untuk menurunkan tingkat kecemasan pada pasien dirumah sakit. Salah satu pendekatan keyakinan spiritual yang diberikan yaitu berupa peemberian terapi dzikir (Paradisi, 2012).

Secara fisiologis, terapi spiritual dengan berdzikir atau mengingat Allah menyebabkan otak akan bekerja, ketika otak mendapatkan rangsangan dari luar maka otak akan memproduksi zat kimia yang akan memberi rasa nyaman yaitu endorphin. Setelah otak memproduksi hal 
tersebut, maka zat ini akan menyangkut dan diserap didalam tubuh yang kemudian akan memberi umpan balik berupa ketenangan yang akan membuat tubuh jadi rileks. Apabila secara fisik tubuh sudah rileks, maka kondisi psikisnya juga merasakan perasaan tenang sehingga mampu untuk menurunkan kecemasan (Hannan, 2014).

Menurut Faruq (dalam Hannan, 2014) mengatakan dzikir adalah sebagai intervensi yang dapat digunakan perawat untuk memenuhi kebutuhan dasar manusia khususnya pada pasien pre dan post operasi dengan masalah kecemasan, dimana dengan melakukan dzikir kepada Allah SWT dalam kurun waktu yang tidak terlalu lama akan memberikan ketenangan pada kondisi kejiwaan (psikis).

Menurut Taufik dalam Perdana (2015) menegaskan bahwa bimbingan spiritual berupa do'a, dzkir, shalat, dan membaca Al-Qur'an mengakibatkan tubuh merespon dengan mensekresi beberapa hormon tertentu sehingga mampu menimbulkan rasa percaya diri, rasa optimisme, mendatangkan ketenangan, damai, dan merasakan kehadiran Tuhan sehingga dapat membantu mengurangi stress dan kecemasan.

Sebagaimana firman Allah SWT dalam Al-Qur'an yang menegaskan bahwa dzikir bermanfaat bagi kehidupan orang yang beriman dan dzikir menentramkan hati dan pikiran, yang berbunyi :

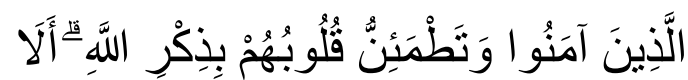

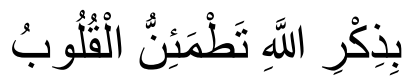

"Yaitu orang-orang yang beriman dan hati mereka menjadi tenteram dengan mengingat Allah. Ingatlah, hanya mengingat Allah hati menjadi tenteram (Q.S ar-Ra'ad;28)"
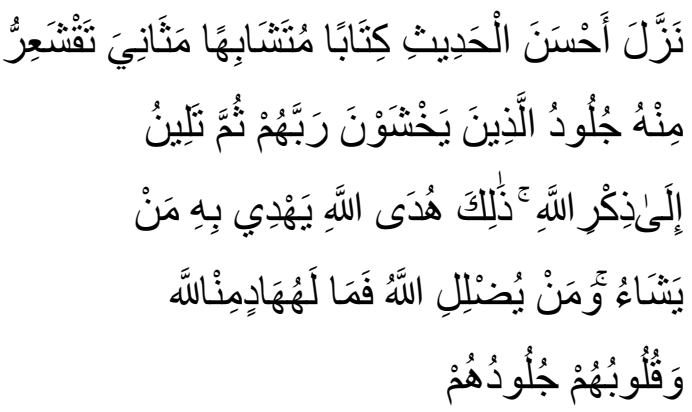

"Gemetar karenanya kulit orang-orang yang takut kepada Allah. Kemudian menjadi tenang kulit dan hati mereka diwaktu mengingat Allah"(Q.S az-Zumar;23).

Dari hasil penelitian terdahulu oleh Yulisa (2012) di RS Muhamadiyah Bantul Yogyakarta tentang pengaruh dzikir terhadap tingkat kecemasan pada pasien pre operasi sectio saecarea (SC) dengan jumlah sampel sebanyak 15 orang didapatkan hasil yang signifikan yaitu $p$ value $0,001<0,05$. Kesimpulannya adalah ada pengaruh dzikir terhadap tingkat kecemasan pada pasien pre operasi sectio saecarea (SC). Penelitian ini juga didukung oleh Utomo dkk. (2016) menyebutkan bahwa ada pengaruh relaksasi dzikir terhadap penurunan kecemasan pada pasien pre operasi TURP di RS Roemani Muhammadiyah Semarang yang dibuktikan dengan didapatkannya $p$ 
value sebesar $0,000<0,05$.

\section{METODE}

Jenis penelitian ini merupakan penelitian kuantitatif dengan menggunakan rancangan penelitian two group pretespostest design. Populasi dalam penelitian ini yaitu sebanyak 3947 Besar sampel yang digunakan dalam penelitian adalah sebanyak 15 orang pasien pre dan post operasi Teknik sampling dalam penelitian "pengaruh terapi dzikir terhadap tingkat kecemasan pada pasien pre dan post operasi" adalah consecutive sampling.

\section{HASIL}

\section{a. Kecemasan Pre Operasi}

Hasil penelitian berdasarkan pada tabel 1 menunjukan bahwa pada awalnya tingkat kecemasan pasien pre operasi sebelum diberikan terapi dzikir sebagian besar responden mengalami kecemasan pada tingkat kecemasan ringan, yaitu sekitar8 orang $(53,3 \%)$, kecemasan sedang sebanyak 5 orang $(33,3 \%)$, serta 2 orang responden $(13,3 \%)$ mengalami kecemasan berat. Sedangkan berdasarkan penelitian sesudah pemberian terapi dzikir, sebagian besar pasien pre operasi tidak mengalami kecemasan yaitu sekitar 7 orang $(46,7 \%)$, kecemasan ringan sebanyak 6 orang (40\%), serta kecemasan sedang sebanyak 2 orang (13,3\%).Dari 8 orang pasien pre operasi yang berada pada tingkat kecemasan ringan sebelum pemberian terapi dzikir, terdapat 2 orang yang tetap berada pada tingkat kecemasan ringan dan 6 orang sudah tidak lagi mengalami kecemasan. Sedangkan dari 5 orang pasien preoperasi yang mengalami kecemasan sedang sebelum pemberian terapi dzikir, terdapat 4 orang pasien yang mengalami penurunan kecemasan menjadi kecemasan ringan dan 1 orang pasien tetap pada tingkat kecemasan sedang. Serta dari 2 orang pasien pre operasi yang mengalami kecemasan berat sebelum pemberian terapi,masing-masing mengalami penurunan kecemasan menjadi kecemasan ringan dan sedang sesudah diberikan terapi dzikir.

Banyaknya angka responden diatas yang mengalami kecemasan diatas normal dikaitkan dengan faktor-faktor resiko yang dapat menimbulkan kecemasan pada pasien pre operasi, misalnya merasa takut karena akan menghadapi ruang operasi, peralatan operasi, takut nyeri setelah pembedahan, takut terjadi perubahan pada bentuk tubuh, takut keganasan bila diagnosa yang ditegakkan belum pasti, takut mengalami kondisi yang sama dengan orang lain yang mempunyai penyakit yang sama, kurang pengetahuan terhadap tindakan yang akan dilakukandan takut akan mati bila operasi gagal (Arif, 2013).

Perubahan kecemasan yang terjadi setelah adanya eksperimen dapat terjadi karena adanya pengaruh pemberian terapi dzikir yang dilakukan selama 12 menit.Perubahan kecemasan tersebut akan berdampak pada kelancaran jalannya proses operasi, dimana 
pasien yang tidak mengalami cemas akan cenderung memiliki denyut nadi, tekanan darah, suhu tubuh, dan daya tahan tubuh yang normal sehingga operasi dapat berjalan dengan lebih efisien dibandingkan dengan pasien yang mengalami kecemasan (Wicaksono, 2015).

Hal tersebut sesuai dengan penelitian dari Nurbaeti (2015) yang mmenyatakan bahwa penyebutan nama Allah secara berulang-ulang (dzikir) akan membuat seseorang merasa tenangdan membantu individu membentuk persepsi yang lain selain cemas yaitu keyakinan bahwa stressor apapun akan dapat dihadapi dengan baik dengan bantuan Allah. Kalimat dzikir sendiri mengandung makna positif, sehingga pikiran negatif yang dialami seorang yang cemas akan diganti dengan pikiran positif ketika individu tersebut berfokus pada kalimat dzikir.

Pendapat ini juga didukung oleh penelitian dari Najati (2009) dikutip dalam Nida (2014) yang menjelaskan bahwa ketika seseorang berdzikir akan membangkitkan rasa percaya diri, kekuatan, perasaan aman, tenteram dan bahagia sehingga aktivitas ini merupakan suatu bentuk terapi bagi segala macam bentuk kegelisahan yang biasa dirasakan seseorang saat mendapati dirinya lemah dan tidak mampu menghadapi tekanan atau bahaya.

Penelitian ini sejalan dengan penelitian yang dilakukan sebelumnya oleh Yuliza (2012) tentang "Pengaruh Dzikir Terhadap Tingkat Kecemasan Pada Pasien Pre Operasi SC di RS Muhammadiyah Bantul Yogyakarta" bahwa hasil tingkat kecemasan dari 15 responden sebelum diberikan terapi dzikir berada pada tingkat kecemasan ringan (60\%), kecemasan sedang (30\%), dan kecemasan berat (10\%).Sedangkan setelah diberikan terapi dzikir mengalami penurunan yang signifikan yaitu pada tingkat kecemasan ringan (100\%).

Dan juga sejalan dengan penelitian dari Perdana (2015) tentang "Pengaruh Relaksasi Dzikir Terhadap Penurunan Kecemasan Pasien Pre Operasi TURP di RS Roemani Muhammadiyah Semarang" bahwa rata-rata penurunan skor kecemasan dari 16 responden sebelum diberikan intervensi yaitu 46,3 (cemas sedang) dan setelah diberikan intervensi mengalami penurunan sebesar 18,1 (cemas ringan).

Menurut asumsi peneliti dalam penelitian ini mengatakan bahwa terdapat perbedaan tingkat kecemasan pada pasien pre operasi sebelum dan sesudah diberikan intervensi terapi dzikir, ini dibuktikan dengan responden yang sebelum diberikan terapi dzikir mengalami penurunan tingkat kecemasan yang signifikan sesudah diberikan intervensi terapi dzikir.Asumsi ini diperkuat oleh teori penelitian dari Utomo (2016) yang menegaskan bahwa pasien pre operasi mengalami penurunan tingkat kecemasan setelah diberikan bimbingan spiritual berupa do'a dan dzikir.Hal tersebut dikarenakan tingkat kepercayaan yang tinggi terhadap kekuatan do'a dan dzikir yang mampu memberikan kemudahan, ketenangan, serta menumbuhkan rasa percaya diri bagi pasien dalam menjalani tindakan operatif. 


\section{Kecemasan Post Operasi}

Hasil penelitian berdasarkan pada tabel 2 menunjukan bahwa rata-rata tingkat kecemasan pasien postoperasi sebelum diberikan terapi dzikir sebagian besar berada pada tingkat kecemasan ringan, yaitu 10 orang $(66,7, \%)$, kecemasan sedang sebanyak 1 orang $(26,7 \%)$ dan 4 orang $(6,7 \%)$ berada pada tingkat kecemasan normal (tidak ada kecemasan). Sedangkan berdasarkan penelitian sesudah diberikan intervensi dzikir diperoleh bahwa tingkat kecemasan pasien post operasi lebih banyak terdapat pada kategori tingkat kecemasan normal (tidak ada kecemasan) sebanyak 13 orang $(86,7 \%)$, dan lebih rendah pada kecemasan ringan sebanyak 2 orang $(13,3 \%)$.Dari 10 orang pasien post operasi yang berada pada tingkat kecemasan ringan sebelum pemberian terapi dzikir, terdapat 2 orang yang tetap berada pada tingkat kecemasan ringan dan 9 orang sudah tidak lagi mengalami kecemasan. Sedangkan dari 4 orang pasien post operasi yang mengalami kecemasan normal sebelum pemberian terapi dzikir, tetap berada pada tingkat kecemasan normal (tidak ada kecemasan) hanya saja skornya yang mengalami perubahan.

Dari data tersebut menunjukkan bahwa sebagian besar kecemasan pada pasien postoperasi, baik sebelum maupun sesudah diberikan diberikan terapi dzikir sudah mengalami penurunan dibanding kecemasan preoperasi. Penurunan kecemasan tersebut disebabkan karena berbagai alasan, seperti halnya terlewatinya masa operasi yang menjadi momok menakutkan bagi pasien. Secara umum, kecemasan yang dialami pada pasien postoperasi tersebut dapat disebabkan oleh gejala-gejala yang muncul setelah dilakukan operasi, diantaranya yaitu rasa nyeri yang dirasakan dan proses penyembuhan luka akibat trauma.

Hal tersebut sesuai denganpenelitian yang dilakukan olehMaisyaroh (2015) yang menyatakan bahwa masalah yang sering muncul yang biasanya jadi penyebab kecemasan yang dialami pada pasien postoperasi saat setelah sadar yaitu dengan edema, nyeri, imobilisasi, keterbatasan dan penurunan kekuatan otot, perubahan bentuk tubuh, perubahan warna, serta penurunan kemampuan untuk ambulasi dan berjalan karena luka bekas operasi dan luka bekas trauma.

Penelitian ini sejalan dengan penelitian dari Rahmawati (2015) tentang "Pengaruh Dzikir Terhadap Mekanisme Koping Pasien Post Operasi Open Prostatectomy di RSUD Sleman Yogyakarta" bahwa dengan analisis data menggunakan menggunakan uji Mann Whitneydari 20 responden menunjukkan bahwa dzikir berpengaruh terhadap mekanisme koping pasien post operasi open prostatectomy dengan nilai $(\mathrm{p}<0,05)$.

Penilitian ini juga sejalan dengan penelitian yang dilakukan oleh Budiyanto (2014) tentang "Pengaruh Terapi Dzikir Terhadap Intensitas Nyeri Pada Pasien Post Operasi CA MAMMAE di RSUD Prof $\mathrm{Dr}$ 
Margono Soekarjo Purwekorto" dengan didapatkan hasil ( $p$ value $0,00<\alpha 0,05)$ maka dapat disimpulkan bahwa terdapat pengaruh terapi dzikir terhadap intensitas nyeri pada pasien post operasi ca mammae, sehingga terapi dzikir sangat bermanfaat terhadap penurunan nyeri post operasi selain terapi farmakologi.

Menurut asumsi peneliti bahwa terdapat perbedaan kecemasan pada pasien post operasi dengan pre operasi. Dalam hal ini kecemasan pada pasien post operasi telah mengalami penurunan, hal ini disebabkan karena pasien telah melewati operasi sehingga pasien tidak lagi merasa dirinya terancam serta tidak lagi merasa takut. Hal ini sesuai dengan penelitian dari Alimansur (2013) yang mengatakan bahwa tingkat kecemasan pasien pasien pada fase pre dan post operasi berbeda, mengingat pengalaman pertama menjalani operasi bisa saja membuat pasien merasa terancam dan pasien merasa pesimis akan kesuksesan operasi yang akan dilakukannya. Berbeda dengan pasien post operasi, disini pasien tidak lagi dalam keadaan akan menghadapi operasi, merasa terancam dan akan dilukai karena pada fase ini pasien telah menjalani operasi itui sendiri.

3. Menganalisis pengaruh terapi dzikir terhadap tingkat kecemasan pada pasien pre dan post operasi antara masing-masing sebelum dan sesudah diberikan terapi dzikir.

Berdasarkan tabel 3 hasil analisis menggunakan uji statistik t-berpasangan dengan tingkat kepercayaan $(\alpha=0,05)$.
Berdasarkan hasil uji ini, didapatkan nilai $p=$ 0,000 dengan demikian $p<\alpha(0,000<0,05)$, maka Ho ditolak dan Ha diterima. Begitupun juga dengan tabel 4.dengan menggunakan uji statistik t-berpasangandengan tingkat kepercayaan $(\alpha=0,05)$. Berdasarkan hasil uji ini, didapatkan nilai $p=0,000$ dengan demikian $p<\alpha(0,000<0,05)$, maka Ho ditolak dan Ha diterima.

\section{KESIMPULAN DAN SARAN}

1. Tingkat kecemasan pada pasien pre operasi sebelum diberikan terapi dzikir yang terbanyak yaitu tingkat kecemasan ringan.

2. Tingkat kecemasan pada pasien pre operasi sesudah diberikan terapi dzikir yang terbanyak yaitu pada tingkat kecemasan normal (tiidak ada kecemasan).

3. Tingkat kecemasan pada pasien post operasi sebelum diberikan terapi dzikir yang terbanyak yaitu pada tingkat kecemasan ringan.

4. Tingkat kecemasan pada pasien post operasi sesudah diberikan terapi dzikir yang terbanyak yaitu pada tingkat kecemasan normal (tidak ada kecemasan).

5. Ada pengaruh terapi dzikir terhadap tingkat kecemasan pada pasien pre dan post

operasi 


\section{DAFTAR PUSTAKA}

Abdillah, M, F. (2014) Pengaruh Zikir

Terhadap Skor Kecemasan

Mahasiswa

Keperawatan UIN Syarif

Hidayatullah Jakarta Menghadapi

Ujian Skill-Lab.

Skripsi Keperawatan.

Anggraini, W. N., \& Subandi. (2014).

Pengaruh Terapi Relaksasi Zikir

Untuk Menurunkan stres Pada

Penderita Hipertensi Esensial.

Jurnal Intervensi Psikologi, vol 6

No. 1, 81-102.

Arif, M., Prayitno, A. S., \& Hudiono, S.

(2013). Pengaruh Terapi Psiko

Spiritual:Bacaan Dzikir Terhadap

Tingkat Kecemasan Pada Pasien Pre

Operasi. Jendela Nursing Journal,

Vol.2 No.1.

Aspuah, Siti. (2013). Kumpulan Kuesioner dan Instrument Penelitian Kesehatan.

NuhaMedika: Yogyakarta.

Budiyanto, T., Ma'rifah, A. R., \& Susanti, P.

I. (2015). Pengaruh Terapi DzikirTerhadap Intensitas Nyeri

Pada Pasien Post Operasi CA Mammae Di RSUD Prof Dr Margono Soekarjo Purwokorto. Jurnal Keperawatan Maternitas, Vol.3 No.2, 90-96.

Brunner, \& Suddarth. (2001). Buku Ajar Keperawatan Medikal Bedah. Jakarta: Penerbit Buku

Kedokteran EGC.
Dharma, K. K. (2011). Metedologi penelitian keperawatan:

Panduan

Melaksanakan dan Menerapkan Hasil Penelitian. Jakarta : Trans Info Media.

Feist, Jess \& Feist, Gregory. (2010). Teori Kepribadian Edisi 7. Salemba Humanika: Jakarta.

Hannan, M. (2014). Dzikir Khafi Untuk Menurunkan Tingkat Kecemasan. Jurnal

Kesehatan,47-53.

Hawari, Dadang. (2013). Psikologi Untuk Keperawatan Edisi 2. EGC: Jakarta

Harahap, K. A., \& Dalimunthe, R. P. (2008). Dahsyatnya Do'a \& Dzikir. Jakarta: QultumMedia.[ebook], <https://books.google.co.id/b ooks

=terapi+dzikir+terhadap+kesehatan $\&$ focus $=$ searchwithinvolume $\& q=$ ter api+dzikir+terhadap+kesehatan>.

Junaidi, I. (2012). Anomaloi Jiwa. Yogyakarta: Perpustakaan Nasional.

Kozier, Erb, Berman, \& Snyder. (2010). Buku Ajar Fundamental Keperawatan: Konsep, Proses \& Praktik. Jakarta: Penerbit Buku Kedokteran: EGC.

Lestari, T. (2015). Kumpulan Teori Utuk Kajian Pustaka Penelitian Kesehatan. Nuha Medika: 
Yogyakarta.

Muayimaratul F. (2016). Faktor-Faktor

Yang Mempengaruhi Kecemasan

Orang Tua Pada Anak Pre Operasi

Di Ruang Bedah Anak RSUP Dr.M.

Djamil Tahun 2016.

Nida, F. L. (2014). Zikir Sebagai Psikoterapi Dalam Kecemasan Bagi Lansia. Jurnal Bimbingan Konseling Islam , Vol,5 No.1.

Nurbaeti, I. (2015). Efektivitas Dzikrullah

Terhadap Penurunan Kecemasan Dan

Nyeri Persalinan Kala 1 Fase Aktif

Ibu Primigravida. Jurnal Ners, Vol.10

No.1, 30-37.

Nursalam. (2016). Metedologi Penelitian Ilmu Keperawatan. Jakarta: Salemba Medika.

Nursalam. (2016). Manajemen Keperawatan: Aplikasi dalam Praktik Keperawatan Profesional. Jakarta:Salemba Medika.

Paradisi, F. (2012). Efektivitas Terapi Murotal Terhadap Penurunan Tingkat Kecemasan Pasien Pra Operasi. Jurnal Ilmiah Kesehatan, Vol V no 2.

Patimah, I., Suryani, \& Nuraeni, A. (2015). Pengaruh Relaksasi Dzikir Terhadap Tingkat Kecemasan Pasien Gagal Ginjal Kronis Yang menjalani
Hemodialisa. Jurnal Keperawatan , Vol 3 No 1, 18-24.

Perdana, P., \& Niswah, Z. (2015). Pengaruh Bimbingan Spiritual Terhadap Tingkat Kecemasan Pada Pasien Pre Operatif di Ruang Rawat Inap RSUD kajen Kabupaten Pekalongan. Jurnal keperawatan . Pieter, H. Z., Janiwari, B., \& Saragih, M. (2011). Pengantar Psikologi untuk Keperawatan. Jakarta: Kencana Perdana Media.

Rahayu, S. Y., Rahayu, U., \& Maisyaruh, S. G. (2015). Tingkat Kecemasan Pasien Post Operasi Yang Mengalami Fraktur Ekstremitas. Jurnal Keperawatan, Vol 3 no 2.

Rahmawati, U. K. (2015). Pengaruh Dzikir Terhadap Mekanisme Koping Pasien Post Operasi Open Prostatectomy Di Bangsal Alamanda 1 RSUD Sleman Yogyakarta. Jurnal Ilmu Keperawatan .

Safaria, T., \& Saputra, N. E. (2009). Manajemen Emosi (Edisi 1 ed.). Jakarta: Bumi Aksara.

Sanusi, M. (2012). Berbagai Terapi Kesehatan Melalui Amalan-Amalan Ibadah. Yogyakarta: Najah.

Setiadi. (2013). Konsep dan Praktik Penulisan Riset Keperawatan (Edisi 2 ed.). Yogyakarta: Graha Ilmu. 
Setiawan, A \& Alimanshur Moh (2013) Perbedaan Tingkat Kecemasan Pada Pasien Pre dan Post di Ruang Seruni RSUD Pare. Jurnal Ilmu Kesehatan, Vol 1 no 2 .

Sugiyono. (2012). Statistika Untuk

Penelitian. Alfabeta: Bandung.

Sujarweni, W. (2014). Metodologi Penelitian Keperawatan.

Yogyakarta: Gava Media.

Wicaksono, A (2015) Pengaruh Sesi

Berdoa Terhadap Penurunan Tingkat Kecemasan Pasien Pre Operasi Di

Bangsal Bedah RSU PKU

Muhammadiyah Bantul Yogyakarta.

Skripsi Keperawatan. 
Tabel 1 Distribusi Jumlah Responden Berdasarkan Jenis Kelamin Pada Pasien Pre dan Post Operasi.

\begin{tabular}{ccc}
\hline \multirow{2}{*}{ Jenis Kelamin } & \multicolumn{2}{c}{ Pre dan Post Operasi } \\
\cline { 2 - 3 } & Frekuensi (f) & Persentase (\%) \\
\hline Laki-Laki & 8 & 53.33 \\
\hline Perempuan & 7 & 46.67 \\
\hline Jumlah & 15 & 100 \\
\hline \multirow{2}{*}{ Usia } & \multicolumn{2}{c}{ Pre dan Post Operasi } \\
\cline { 2 - 3 } & Frekuensi (f) & Persentase (\%) \\
\hline Dewasa Awal & 9 & 60 \\
\hline Dewasa Akhir & 6 & 40 \\
\hline Jumlah & 15 & 100
\end{tabular}

Sumber : Data Primer

Tabel 2 Distribusi Jumlah Responden Berdasarkan Tingkat Kecemasan Pada Pasien Pre Operasi.

\begin{tabular}{ccccc}
\hline \multirow{2}{*}{$\begin{array}{l}\text { Tingkat } \\
\text { Kecemasan }\end{array}$} & Pre test & $\%$ & Pos test & $\%$ \\
\cline { 2 - 5 } $\begin{array}{c}\text { Tidak Ada } \\
\text { Kecemasan }\end{array}$ & 0 & 0.0 & 7 & 46.7 \\
\hline Ringan & 8 & 53.3 & 6 & 40.0 \\
\hline Sedang & 5 & 33.3 & 2 & 13.3 \\
\hline Berat & 2 & 13.3 & 0 & 0.0 \\
\hline Jumlah & 15 & 100.0 & 15 & 100.0 \\
\hline
\end{tabular}

Sumber: Data Primer

Tabel 3 Distribusi Jumlah Responden Berdasarkan Tingkat Kecemasan Pada Pasien Post operasi.

\begin{tabular}{ccccc}
\hline \multirow{2}{*}{$\begin{array}{c}\text { Tingkat } \\
\text { Kecemasan }\end{array}$} & Pre test & $\%$ & Pos test & $\%$ \\
\cline { 2 - 5 } $\begin{array}{c}\text { Tidak Ada } \\
\text { Kecemasan }\end{array}$ & 4 & 26.7 & 13 & 86.7 \\
\hline Ringan & 10 & 66.7 & 2 & 13.3 \\
\hline Sedang & 1 & 6.7 & 0 & 0.0 \\
\hline Berat & 0 & 0.0 & 0 & 0.0 \\
\hline Jumlah & 15 & 100.0 & 15 & 100.0 \\
\hline
\end{tabular}

Sumber: Data Primer 
Tabel 4 Analisis Perbedaan Tingkat Kecemasan Pada pasien Preoperasi Sebelum dan Sesudah Pemberian Terapi Dzikir.

\begin{tabular}{ccccc}
\hline Kelompok & Intervensi & $\mathrm{N}$ & Mean & p value \\
\hline \multirow{2}{*}{ Preoperasi } & Sebelum & 15 & 48.3 & \multirow{2}{*}{$<0,001$} \\
\cline { 2 - 4 } & Sesudah & 15 & 38.2 & \\
\hline
\end{tabular}

Sumber: Uji T Berpasangan

Tabel 5 Analisis Perbedaan Tingkat Kecemasan Pada Pasien PostOperasi Sebelum dan Sesudah Pemberian Terapi Dzikir.

\begin{tabular}{ccccc}
\hline Kelompok & Intervensi & $\mathrm{N}$ & Mean & p value \\
\hline \multirow{2}{*}{ Postoperasi } & Sebelum & 15 & 38.8 & \\
\cline { 2 - 4 } & Sesudah & 15 & 31.7 & \\
\hline
\end{tabular}

Sumber: Uji T Berpasangan 